\title{
Dominio y catástrofe. Los terremotos en Concepción, Chile: 1550-1751/
}

\author{
Domain and Catastrophe. The Earthquakes \\ in Concepcion, Chile: $1550-1751$
}

Alfredo Palacios Roa

Universidad de Chile

En la ciudad chilena de Concepción, las catástrofes parecieron manifestarse según la voluntad humana. Ésta fue una de las condiciones que los habitantes de su suelo intentaron imponerle a la naturaleza para así superar, arquitectónicamente hablando, sus órdenes y dinámicas. En este contexto, el presente artículo analiza la transformación de aquella legendaria urbe con relación al efecto destructor de los terremotos y tsunamis que la afectaron desde su fundación hasta su traslado en 1751.

Palabras Claves: Chile; Concepción; Catástrofes; Terremotos; Urbanismo.

In the Chilean city of Concepcion, the catastrophes seem to appear according to human will. This was one of the conditions that the inhabitants of that place tried to impose on nature in order to overcome, architecturally talking, its orders and dynamics. Thus, this present article tries to analyze the transformation of that legendary urbe in relation to the destructive effect of earthquakes and tsunamis that affected it since its foundation to its transfer in 1751.

Keywords: Chile; Concepcion; Catastrophe; Earthquakes; Urbanism. 


\section{Introducción}

Históricamente, diversos fenómenos meteorológicos y geológicos afectaron constantemente a la antigua ciudad chilena de Concepción, desde su declarada y abierta proposición de superar, arquitectónicamente hablando, las manifestaciones de la naturaleza. Relatos, grabados, mapas y diversos testimonios reseñan e ilustran aquellas experiencias, manteniendo y conservando en la memoria colectiva estos «infaustos» episodios. ${ }^{1}$ Por lo tanto, el escribir a partir de la idea de los desastres causados por los peligros naturales como posible símbolo de la cultura penquista, supone ingresar a un mundo completamente distinto que despliega un imaginario diferente, donde las relaciones entre el hombre y su entorno cobran -a cada instante y de forma reiterada- un nuevo significado.

En este contexto, ¿cuál vendría a ser esta conceptualización desde una perspectiva urbana?, o bien ¿cuáles serían las posibilidades de comprender y analizar la memoria que intenta recuperar los momentos contradictorios de la relación existente entre los desastres y la sociedad penquista colonial? Para responder a tales interrogantes, se han analizado un conjunto de fuentes históricas, tanto en Chile como en España, en las que los fenómenos naturales aparecen como los eternos enemigos de la tranquilidad espiritual y del progreso material de los habitantes de la antigua ciudad de Concepción. ${ }^{2}$

Teniendo en consideración lo anterior, el presente artículo se puede convertir en un aporte significativo ya que, al utilizar descripciones inmediatas al acontecer de los hechos, es posible recrear el desarrollo de la catástrofe, no solo desde una plataforma urbana o arquitectónica, sino también social y cultural, al conocer las formas en que se incorporaba al imaginario colectivo y originaba un modus operandi particular que permitía restablecer el orden en la afectada comunidad.

1 Mellafe, 1980, 121-128.

2 Para efectos de esta investigación entenderemos «fenómeno natural» como cualquier manifestación de la naturaleza resultante de su funcionamiento interno, y «desastre» —o «catástrofe» en cuanto a sinónimo, y que se utilizará en forma indistinta en este trabajo- como fenómenos que afectan directamente a las personas y sus actividades, y que provocan daños de consideración a las infraestructuras, empeorando las condiciones de vida de diversos sectores de la población al alterar su actividad cotidiana. Espinoza, 1990, 21. Maskrey; Romero, 1993, 7. 


\section{Antecedentes para nuestro enfoque}

El estudio de los desastres causados por los peligros naturales promovió, una vez finalizado el denominado «Decenio Internacional para la Reducción de los Desastres Naturales (DIRDN, 1990-1999)», , la aplicación de un cambio conceptual a través del desarrollo de investigaciones y acciones internacionales orientadas a lograr la reducción de los efectos causados por los mismos.

Ciertamente, los grupos de investigación que se dedican al tema han concluido que no existe ninguna ciudad que se encuentre libre de verse afectada por algún tipo de evento de origen natural que sea destructivo, como por ejemplo terremotos, tsunamis, erupciones volcánicas, inundaciones y huracanes. Se insiste en que lo más importante es saber resolver las situaciones coyunturales, y luego tener la capacidad de recuperación, la que en cada comunidad, y dependiendo del fenómeno concreto que la afectó, sería distinta (es lo que se denomina resiliencia) $;{ }^{4}$ de este modo, e intentando criterios de estudio y acción, la comunidad científica llegó a un acuerdo generalizado con respecto a tres conceptos básicos:

Peligros Naturales: representan los efectos físicos de un proceso natural potencialmente perjudicial. ${ }^{5}$

Vulnerabilidad: describe el grado de resistencia o susceptibilidad de un sistema socioeconómico con respecto al impacto de los peligros naturales; por lo tanto, el grado de vulnerabilidad (de 0 a 100\%) se determinará por una combinación de factores, incluyendo la concienciación existente sobre estos peligros, las condiciones que presentan las poblaciones y la infraestructura, junto con las políticas relacionadas con la gestión de los desastres. ${ }^{6}$

Riesgo: probabilidad de consecuencias perjudiciales o pérdidas esperadas (muertes, lesiones, propiedad, medios de subsistencia, interrupción de la actividad económica), resultado de interacciones entre procesos naturales y condiciones de vulnerabilidad. ${ }^{7}$

Complementando lo anterior, y con el fin de evitar la confusión que puede generar el uso de los términos «fenómeno natural» $\mathrm{y}$ «desastre»,

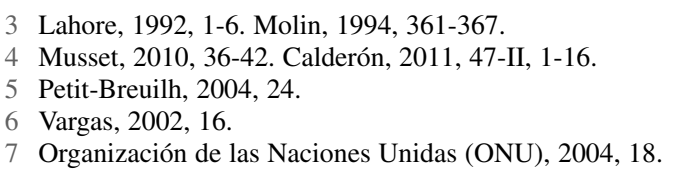


debemos decir que algunos fenómenos naturales son destructivos, pero no siempre causan desastres, como, por ejemplo, un terremoto que ocurre en una zona despoblada; en definitiva, un desastre es siempre un producto social en el cual el proceso físico no determina necesariamente el resultado, ${ }^{8}$ en otras palabras, existe el riesgo de que ocurra un desastre cuando uno o más peligros naturales se manifiestan en un contexto vulnerable, por lo que una evaluación de riesgo debe considerar la siguiente ecuación: Riesgo $=$ Peligro + Vulnerabilidad ${ }^{9}$

Ahora bien, de la mencionada ecuación se pueden desprender dos enfoques para analizar los desastres. El primero, y el más extendido, ha tomado como punto de partida la idea de que los desastres son característicos de procesos naturales peligrosos; es decir, que los peligros naturales son los elementos que determinan el carácter del desastre, articulando así lo que algunos investigadores han denominado en sus trabajos como «naturaleza violenta y desenfrenada». ${ }^{10} \mathrm{El}$ segundo, el menos difundido, considera que el elemento activo de los mismos es la vulnerabilidad y los procesos y estructuras socioeconómicas que la conforman, en otras palabras sería la vulnerabilidad la que determina el carácter y alcance de los desastres. ${ }^{11}$ Sobre este último punto, la Comisión Económica para América Latina y el Caribe (CEPAL) - dentro del marco del mejoramiento de la metodología empleada en la evaluación de los daños causados por los desastres-, además de puntualizar los factores y definir las tres categorías de la vulnerabilidad (la exposición destructiva ante una determinada amenaza, la incapacidad de reaccionar adecuadamente cuando la amenaza se presenta y la incompetencia para lograr la recuperación de las condiciones de vida normales), presentó el siguiente esquema para entender de mejor manera su funcionamiento y aplicación: Vulnerabilidad $=f$ (Grado de Exposición, Resistencia). ${ }^{12}$

Dentro de esta lógica, el énfasis puesto en la vulnerabilidad como el «agente activo» de los desastres y no el fenómeno natural en sí mismo, constituye una interpretación válida para nuestro estudio; en efecto, y par-

8 Herzer, 1990, 5.

9 Maskrey, 1989, 19.

10 Gascón, 2006, 2, 65-66. Alberola, 2009, 17-76.

11 Maskrey, 1989, 20.

12 Vargas, 2002, 16. Para efectos de esta ecuación, el «grado de exposición» corresponderá al tiempo y modo sometido de un ecosistema a los efectos de una actividad potencialmente peligrosa, es decir, cuanta energía potencialmente destructiva recibe y por cuánto tiempo; y «resistencia» como la capacidad de las sociedades humanas para hacer frente a los desastres. 
tiendo de la base de que la vulnerabilidad no se determina por «peligros naturales», sino por ciertos procesos sociales, económicos y políticos, las regiones más vulnerables serían aquellas que presentan mayores índices de pobreza y un mayor grado de dependencia. De esta manera, y tal como lo explica la especialista Virginia García, esta desfavorable situación sería el resultado de la evolución de múltiples procesos sociales y económicos que, asociados a determinadas condiciones geofísicas, elevan el porcentaje de vulnerabilidad de determinadas sociedades; ${ }^{13}$ por lo tanto, y teniendo en cuenta estos aspectos, podemos decir que los fenómenos naturales no serían necesariamente los agentes que provocan el desastre, puesto que solo se convertirían en el «detonador» de una situación crítica preexistente. A este respecto, el investigador chileno Alfredo Rodríguez, al hablar de aspectos «no-naturales» de los efectos de los eventos naturales, indica que muchas veces éstos alcanzan la categoría de «desastres» por falta de previsión, o bien por la precaria realidad de algunas poblaciones; por lo que, al momento de desencadenarse un peligro natural, se desvelaría una parte de la realidad urbana que permanecía oculta, esto es: poblaciones precarias, materiales de construcción inadecuados, fábricas mal ejecutadas, localizaciones inadecuadas, etc..$^{14}$

En consecuencia, y en base a estos aportes teóricos, en las siguientes páginas daremos a conocer las alternativas desarrolladas por los habitantes de la vieja ciudad de Concepción en su intención por superar la dinámica de la naturaleza.

\section{La fundación de Concepción y sus primeros registros catastróficos}

En el curso de esta investigación, las primeras experiencias catastróficas registradas en la ciudad de Concepción datan a partir de 1536, cuando el riguroso clima afectó seriamente a la hueste dirigida por Diego de Almagro. En la ruta cordillerana, el mencionado descubridor se encontró con las torrenciales lluvias del verano y, si bien llegó hasta el cultivado y fértil valle del río Aconcagua, las noticias que le trajo desde el sur su capitán Gómez del Alvarado en pleno invierno del citado año, unidas a la falta del oro que iban buscando, lo hicieron regresar al Perú.

13 García, 1992, 24-25.

14 Rodríguez, 1990, 30, 11-12. 
La difamación que hizo el citado adelantado del suelo chileno, no fue impedimento alguno para que Pedro de Valdivia dedicase su vida a conquistarlo y, en su intento por fundar una ciudad en el sur del territorio recién descubierto, se adentrara en el terreno araucano-mapuche.

Viendo que el número y arrojo de los indígenas hacían imposible la exploración de la región más allá del río Biobío, el extremeño se dirigió con su tropa hacia el mar en busca de una hermosa y abrigada bahía que, según dejó escrito su secretario Gerónimo de Vivar, «había visto el gobernador cuando vino el año de mil y quinientos cuarenta y cuatro donde dijo que había que poblar una ciudad cuando allá tornase». ${ }^{15}$ De este modo, Valdivia —al mando de una hueste de 200 hombres - llegó al valle de Andalién en febrero de 1550 y se detuvo allí durante dos días. En aquel sitio, el 22 de febrero, los indígenas - que según el conquistador sobrepasaban los vente mil- ${ }^{16}$ asaltaron su campamento pero los peninsulares, ante tal embestida, no fueron sorprendidos, gracias a que el fundador de la ciudad de Santiago había dispuesto que la mitad de los soldados velara el asentamiento mientras dormía la otra mitad. En el lugar, se libró una dura contienda en la que el valor y el número de los indígenas pusieron a los españoles en desesperado aprieto, pero las armas europeas hicieron estragos entre los naturales, que no contaban con instrumentos defensivos; como consecuencia, la victoria no tardó en declararse a favor de los hispanos.

Un solo muerto tuvieron los españoles pero, según el mismo conquistador, «sesenta caballos y otros tantos cristianos» ${ }^{17}$ quedaron heridos $\mathrm{y}$, según otros, ninguno de los españoles combatientes escapó sin herida. ${ }^{18}$ Lo cierto es que la ardiente fe de los españoles atribuyó el éxito de aquella jornada a la milagrosa intervención del apóstol Santiago, una figura decisiva en los enfrentamientos bélicos que sostuvieron entre los siglos XVI y XVII. De esta manera, según refiere el cronista y militar Pedro Mariño de Lobera, «muy regocijados quedaron los cristianos con esta memorable victoria» ${ }^{19}$ y ello, siguiendo su interpretación, reforzó aún más la idea de fundar una ciudad en aquellas tierras. El sitio en concreto aún no se escogía, lo que sí se había definido era el nombre con el cual bautizarían a la futura ciudad: La Concepción de María Purísima.

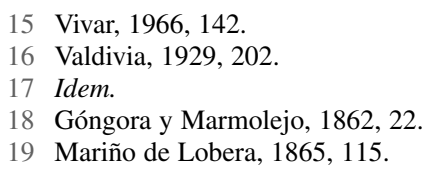


Para cimentar tal objetivo, el gobernador escogió un terreno en una zona apacible y libre de enemigos. Siguiendo algunos relatos juzgó como el sitio más cómodo un paraje que, rodeado de árboles y acompañado de una extensa bahía, le daban al lugar - llamado por los indígenas Penco- ${ }^{20}$ los atributos necesarios para ser el terreno donde fundar la ciudad castrense. Habiendo caminado unas dos leguas (aproximadamente unos once kilómetros), y dejando atrás el lugar que precedió a la batalla, se llegó al espacio que ya está dicho e inmediatamente puso en ejecución su decisión. De todo ello, el mencionado Pedro de Valdivia dio cuenta a sus apoderados de la Corte por carta fechada en Concepción el 15 de octubre de 1550:

...informar cómo a los xxiij de hebrero pasé allí el campo e hice un fuerte, cercado de muy gruesos árboles, espesos, entretejidos como seto, e haciendo un ancho e hondo foso a la redonda, a la lengua del agua e costa de la mar en un puerto e bahía el mejor que hay en estas Indias. ${ }^{21}$

En esta situación, Pedro de Valdivia pensó crear una ciudad que, estando de Santiago casi a igual distancia que La Serena, sirviera de cuartel general a la conquista de la vasta región que acababa de recorrer con sus tropas. Por otra parte, sus condiciones geográficas como lo abrigado y seguro de la bahía, la fertilidad de los campos contiguos, la abundancia de aguas, la fácil defensa de aquel valle, por estar rodeado de altos cerros cubiertos de bosques impenetrables y la proximidad del río Biobío — que sería la base de la futura línea de operaciones contra los araucanos-, iban a ser razones poderosas para designar a aquel lugar como el más conveniente para organizar la nueva urbe. En efecto, el 3 de marzo de 1550, el conquistador trazó su planta, repartió encomiendas y entregó solares a sus compañeros para luego dirigir la construcción de casas provisionales que ayudasen a capear el invierno que se avecinaba. En consecuencia, la proximidad de esta estación lluviosa forzó el retraso de la ceremonia oficial de fundación hasta la entrada de la primavera. Llegada aquella estación, se determinó celebrar solemnemente la creación de la nueva ciudad, y el día escogido para tal evento fue el domingo 5 de octubre de 1550; durante aquella jornada, en su carta de relación a Carlos V, Valdivia indicaba que:

20 Penco en mapudungun significa agua del peumo, un árbol perenne originario del centro y sur de Chile. Matus (ed.), 2005, 247. Debido a su primera ubicación en este sitio, el gentilicio adoptado por la ciudad y sus habitantes fue «penquista».

21 Valdivia, 1929, 136. 
poblé este asiento y fundé una ciudad y nombrela de la Concepción del Nuevo Extremo. Formé cabildo, justicia y regimiento, y puse árbol de justicia [...] y señalé vecinos, y repartí los caciques entre ellos; y así viven contentos, bendito Dios. ${ }^{22}$

Once días más tarde, el nuevo cabildo confirió poder a Alonso de Aguilera para que gestionara en la Corte hispana mercedes y prerrogativas para la nueva urbanización. El procurador cumplió su cometido y, entre otras peticiones, solicitó para Concepción un escudo de armas cuyos blasones, por real cédula del 5 de abril de 1552, quedaron dispuestos de la siguiente forma:

un águila negra en el campo de oro i por una orla un sol de oro encima de la dicha águila i a los pies una luna de plata i a los lados cuatro estrellas de oro i dos ramos de azucenas de su color en campo azul..$^{23}$

Tal fue la fundación de Concepción, la primera de las ciudades australes de Chile, ${ }^{24}$ la única urbe que pudo mantener a raya a los agresivos araucanos; la que, con mayor constancia y energía, soportó todo tipo de enfrentamientos bélicos y la que, gracias al indomable tesón de sus habitantes, llegó a un insospechado grado de prosperidad y grandeza, venciendo los obstáculos que frecuentemente le imprimía la naturaleza. Todo esto sucedió hasta el mes de mayo de 1751, cuando un nuevo proceso geológico combinado obligó a su traslado.

\section{El primer gran terremoto}

En el Reino de Chile, mientras continuaban sucediéndose enfrentamientos entre los araucano-mapuches y los españoles, se viviría otro catastrófico acontecimiento, pero de naturaleza diversa y desconocida: un paroxismo, el primer gran terremoto que experimentaron los europeos en suelo chileno. ${ }^{25}$

22 Ibidem, 206.

23 Thayer Ojeda, 1911, 802.

24 Lamentablemente no se conserva el acta fundacional de Concepción. Los asaltos indígenas y las constantes destrucciones que provocaron los terremotos y tsunamis terminaron con el antiguo archivo del cabildo, siendo los documentos del viejo Archivo Municipal, que datan desde 1782, los únicos manuscritos que se conservan; el resto de los papeles. Amunátegui Solar, 1930, 3.

25 Algunos historiadores e investigadores mencionan que el primer sismo del que se tenga registro ocurrió en 1520, señalando como fuente al abate Juan Ignacio Molina. Su texto Saggio sulla storia naturale del Chili, publicado por Molina en Bolonia, en 1782, fija como el primero de los más importantes terremotos ocurridos en Chile, el del año de 1570. Posteriormente, la traducción del mismo documento, efectuada por Domingo Joseph de Arquellada en 1788, seguramente por error de trascripción, indica el año de 1520. Molina, 1788, I, 33. 
La ciudad penquista, puesta siempre en armas para prevenir incursiones indígenas, fue el primer centro urbano que experimentó la dinámica de la naturaleza; pues sus pobladores fueron sorprendidos la mañana del 8 de febrero de 1570 por un nuevo y anónimo enemigo. Aquel día, miércoles de ceniza, cerca de las nueve de la mañana, hora en que la mayoría de los vecinos se hallaban en misa, repentinamente sobrevino un temblor tan grande que se cayeron la mayor parte de las casas y se abrió la tierra por tantas partes «que era admirable cosa verlo, de manera que los que andaban por la ciudad no sabían qué hacer, creyendo que el mundo se acababa». ${ }^{26}$ Aquellas líneas se pueden entender porque muchos vieron salir, a través de las grietas que se abrieron en la tierra, grandes borbotones de agua negra con olor a azufre, hecho que asociaron con el hedor del infierno; además, luego del seísmo, fueron testigos de como el mar se retiró más de lo ordinario y «volvió con grandísimo ímpetu y braveza a tenderse por la ciudad». ${ }^{27}$

Los penquistas, al escuchar el ruido estruendoso que precedió al terremoto, dejaron sus casas y salieron a las calles pidiendo a gritos la intercesión de la divina misericordia. Envueltos en el miedo y el espanto, en consideración a los nulos conocimientos que tenían sobre el origen de los procesos naturales, entendieron - dentro de su religiosa y creyente mentalidad- que aquello era el fin del mundo, y por este motivo corrieron a refugiarse en las alturas más cercanas para establecerse provisionalmente. En aquella despavorida huida, algunos comenzaron a preguntarse: ¿a dónde vamos?, ¿podremos escapar del castigo del Señor?; seguramente, con sus oscuros planteamientos intentaban traducir la inédita experiencia en alguna explicación lógica y satisfactoria, que ayudase a aquietar los ánimos y les brindase la posibilidad de tener una respuesta concreta para orientar un correcto actuar frente al ignorado fenómeno.

Siguiendo esta lógica, y en una actitud surgida directamente del temor y no de las características propias del evento, pensaban que si subían a lo alto, al cielo, Dios estaría ahí, y que si retornaban al llano de la ciudad también se encontrarían con él; incluso, otros llegaron mucho más lejos en sus pensamientos, vociferando que si pudieran volar hacia los desiertos o incluso llegar al otro lado del mar también serían alcanzados por el «azote divino». Por lo tanto, muchos habitantes conscientes de sus faltas y de la gra-

26 Góngora y Marmolejo, 1862, 188.

27 Idem. 
vedad de sus pecados, consideraron que la opción no era huir, sino «sufrir al señor, que es Padre y si ahora castiga, después nos regalará». ${ }^{28}$

En este contexto, la arruinada ciudad debió ofrecer un espectáculo dantesco, repleto de escenas de desolación y llanto durante la tarde y la mañana siguiente. Al respecto, el cronista Diego de Rosales expresó que:

las lágrimas, las vozes, los gemidos y los alaridos de hombres y mugeres, viendo perdidas sus haziendas en un instante, la ira de Dios que amenazaba, el castigo con que los afligía, y el temor de sus conciencias, que les acusaba, eran tan grandes que parecía un día de juicio. ${ }^{29}$

Inmerso en esta dura aflicción se encontraba el pueblo penquista cuando el reconocido licenciado Torres de Vera se enteró de la amarga noticia. Rápidamente, por estar próximo a la ruinosa ciudad, se dirigió a ella acompañado de cien soldados, temiendo que los indígenas aprovecharan el caos que les hacía vulnerables, para arrojarse sobre sus indefensos habitantes. Aquella idea se puede explicar, según la óptica peninsular, porque los naturales, al no ser cristianos, no podrían ser víctimas de aquel castigo celestial, quedando incólumes para concretar algún tipo de ataque que pusiera en peligro la vida de los desafortunados creyentes. Es por ello que la llegada del animoso oidor, infundió en los atribulados habitantes cierto grado de optimismo y aliento, tras lo cual emprendieron la construcción de un fuerte con los materiales recuperados de las casas arruinadas para que, una vez concluido, tuviesen la posibilidad de guarecerse en él en caso de ser atacados por los naturales.

Además de esta latente amenaza, había para los habitantes de Concepción otro motivo de alarma: después de pasado el terremoto, la tierra seguía moviéndose aunque con poca violencia, pero con la suficiente magnitud para tener a los vecinos en constante inquietud y vigilia, ya que temían que la catástrofe volviera a repetirse. Aquellas réplicas — que se prolongaron durante más de cinco meses $-{ }^{30}$, impedían a la población regresar a sus casas o lo que quedaba de ellas. Así se entiende que muchos pernoctaran en ranchos cuyos techos fueron construidos con paja y ramas con el objetivo de que, si se caían, no causarían daño.

\footnotetext{
28 Rosales, 1877, II, 184.

29 Idem.

30 Briseño, 1889, 533.
} 
Los vecinos, habitando en estas precarias condiciones, consideraron como especial milagro de la Providencia que nadie hubiera perecido en el terremoto ${ }^{31}$ por lo que determinaron implorar solemnemente la clemencia divina por medio de un protector o abogado celestial. Para cumplir aquel cometido, en el mes de junio de ese mismo año, se reunieron todos en la Iglesia Mayor en cabildo público, presidido por el mismo Torres de Vera, y habiendo echado a la suerte la elección de patrono, ${ }^{32}$ recayó ésta en la Natividad de la Virgen Santísima. Terminada la elección del intermediario, los presentes hicieron voto de edificar una ermita dedicada a esta advocación sobre la loma en que se habían refugiado después de la catástrofe, en acción de gracias. Esta fue, además de la promoción de las reformas de las costumbres y la eliminación de los vicios arraigados en aquella sociedad, la fórmula utilizada, «suerte de remedio infalible», para frenar el comportamiento de la naturaleza; sin embargo, nadie se preocupó por atender las causas concretas del fenómeno que tanto daño les había causado, ni menos pensaron que el suceso podía volverse a repetir, solamente se avocaron a ensalzar la religión y sus símbolos, procurando así contentar a Dios, a quien sindicaban como el autor de tal evento.

En ese sentido, según refiere el cronista Pedro de Córdoba y Figueroa, los vecinos, además de las medidas ya adoptadas:

levantaron una cruz y ofrecieron ir todos los años a vísperas de solemnes las tardes de los miércoles de ceniza, y al dia siguiente tenerle por festivo e ir procesionalmente de la catedral los eclesiásticos de la ciudad, el cabildo secular y todos los vecinos y moradores, descalzos, a celebrar una misa cantada. ${ }^{33}$

Según esta última cita, así se levantó el acta de esta reunión, donde quedó constancia del voto perpetuo, que fue suscrita por los personajes más notables del vecindario; además, en aquel acuerdo - fechado a 8 de julio de 1570 - se constató, según ellos, que, desde que se hizo la promesa y se plantó la cruz en la loma, cesaron definitivamente los temblores. Por lo tanto, e imbuidos en esta confianza, la citada promesa colectiva se cumplió religiosamente durante muchos años; ${ }^{34}$ no obstante, nuevas catástrofes vendrían a desvanecer aquellas ilusiones infundidas en la fe y forjadas por la devoción.

31 Barros Arana, 1884, II, 416.

32 Este procedimiento religioso era frecuente en el mundo hispano durante la época colonial, con el fin de que la divinidad orientase la decisión de los hombres. Ver: Petit-Breuilh, 2002, 338.

33 Córdoba y Figueroa, 1862, 138.

34 Carvallo y Goyeneche, 1875, I, 173. 


\title{
Un nuevo siglo, un nuevo sismo
}

Cuando iban diluyéndose en la memoria de las generaciones penquistas los estragos causados por el terremoto de 1570, se produjo un terremoto que trajo el espanto y turbación a los descendientes de aquellos habitantes que habían logrado levantarse del funesto evento del siglo anterior. Así, y antes de comentar las características de este nuevo proceso geológico, hay que decir que, al despuntar el siglo XVII, la otrora «pequeña ciudad», como fue llamada por Mariño de Lobera, ${ }^{35}$ comenzaba a mostrar cierto grado de adelanto y prosperidad. Por ejemplo, de los treinta vecinos que albergaba en 1580 se aumentó, veinte años más tarde, a un total de setenta personas, ${ }^{36}$ y en 1601, según un detallado informe redactado por el gobernador Alonso de Ribera, había en aquella urbe:

\begin{abstract}
tres conventos Ntra. $S^{\text {a }}$ delas Mercedes, $S^{n}$ Fran $^{\text {co }}$ y $\mathrm{S}^{\text {to }}$ Domingo cada uno de estos con un fraile; de ordinario la iglesia oy tiene un cura y un sacristán; ay un hospital que cuando yo llegué aquí estava por el suelo, casi perdida la memoria del y delas haciendas que tenia [...] la población de esta ciudad es de muy pocas casas y muy ruines de la traza que algunos buhios de paxa sin fora de calles ni ninguna cosa de curiosidad ni republica. ${ }^{37}$
\end{abstract}

Se calcula que para el año de 1610 la ciudad tendría no más de ciento cincuenta casas que, al igual que el resto de los edificios del territorio chileno, estaban construidas de tapias y adobes, y eran humildes en cuanto a altura «porque ninguno tiene más del primer suelo y esto a causa de lo mucho que es sujeto todo aquel reino a terremotos». ${ }^{38}$ Esta era la radiografía general de Concepción al comenzar el siglo XVII, una ciudad cuyo progreso material era muy lento, ya que su animada sociedad tenía en contra dos terribles enemigos: la guerra y las catástrofes.

\section{El segundo cataclismo}

El maestre de campo Martín de Herize y Salinas, comenzaba su relación histórica señalando que:

\footnotetext{
35 Mariño de Lobera, 1865, 115.

36 Guarda, 1978, 43.

37 Gay (comp.), 1852, II, 153.

38 González de Nájera, 1889, 12.
} 
el cometa que por diciembre del año pasado de 52 apareció en la altura de Mayre, discurriendo por más de veinte días desde nuestra América austral a la septentrional de Nueva España, dio mucho que pensar en ambos reinos y especialmente en aquel se predijeron las fatales desgracia, y el común rebelión de los indios chilenos, insinuando ser mucho más lo que se dejaba al silencio de lo que se decía en el pronóstico. ${ }^{39}$

Dentro de aquellos sombríos augurios, de cierta manera justificados por los accidentes y contrastes de la guerra, los cronistas evocan que en uno de los primeros días del mes de marzo de 1657 un muchacho, de entre doce y catorce años, salió de la ciudad a recoger leña a un bosque cercano y, donde terminaba lo poblado, se encontró con un personaje de venerable y sereno aspecto que «le mandó se volviese a la ciudad y le avisase que habría un gran terremoto e inundación de mar». ${ }^{40}$

Rápidamente se esparció aquel rumor por Concepción y muchas personas, temerosas de tan apocalípticos comentarios, acudieron a la casa del niño para cerciorarse de lo que se decía. Ciertamente, y con el correr de los días, la noticia alcanzaba una mayor notoriedad y se transformaba en un tema ineludible en todas las conversaciones. Esta situación obligó al obispo de aquel entonces, fray Dionisio de Cimbrón, junto a otros sacerdotes, a reunirse con el joven para que éste les refiriera lo que había visto y oído. El padre del muchacho, irritado con la masiva cantidad de curiosos que llegaban a su hogar para acreditar tan extraña novedad, procedió a darle unos azotes, tratándolo de visionario, novelero y revoltoso y, en el mismo instante del castigo, según afirman varios testigos, la tierra comenzó a estremecerse. ${ }^{41}$ Cierto o no, el hecho es que a las ocho de la noche del jueves 15 de marzo de 1657 se produjo un movimiento que, al igual que el del siglo anterior, fue precedido por un violento ruido que permitió a los habitantes de la ciudad salir de sus casas. El jesuita Diego de Rosales, testigo ocular de los hechos, señaló en su extensa crónica que aquel seísmo alcanzó tanta fuerza que «en pie no podíamos tenernos: las campanas se tocaban con el movimiento, las casas bambaleaban y se caían a plomo». ${ }^{42}$

En consecuencia, Concepción quedó arruinada no solo por el seísmo, sino también por un tsunami, ya que como dice una relación contemporánea:

\footnotetext{
39 Herize y Salinas, 1879, XIII, 281.

40 Córdoba y Figueroa, 1862, 221.

41 Ibidem, 222.

42 Rosales, 1877, II, 205.
} 

por las calles de la dha. ciudad con que combatida de estos tan fuertes elementos cayeron los edificios y se perdieron los víveres y murieron hta. cuarenta personas. ${ }^{43}$

Ciertamente, dos horas después del primer remezón y luego de que algunos vieran un enorme globo de fuego caer hacia el poniente, ${ }^{44}$ el mar se retiró, pero inmediatamente volvió con un ímpetu aterrador y «bramando saltó las márgenes inundando y arrasando todo lo que había quedado en pié, todo lo que alcanzó su furia que fue hasta la misma plaza». ${ }^{45}$ Cuando esto ocurría, y los espantados habitantes buscaban refugio en las lomas vecinas, el obispo Cimbrón se plantó en medio de la plaza y desafió a pie firme el furor de las olas, conjurándolas en nombre de Dios ${ }^{46}$ — como si ello fuese el prodigio básico - para que se retirasen; sin embargo, esto no ocurrió, y todos los bienes y ajuares de las casas quedaron nadando en aquel mar sin márgenes.

En esta ocasión, no hubo construcción alguna que se eximiese del rigor de la naturaleza. El palacio del gobernador, las Cajas Reales, los almacenes militares, el hospital de San Juan de Dios, así como los tres conventos, quedaron enteramente destruidos; lo mismo pasó con un barco que estaba en la bahía, que tras el terremoto quedó en medio de una laguna situada en los terrenos del arruinado convento de San Agustín. Solamente la iglesia y colegio de la Compañía de Jesús, por encontrarse en un sitio más elevado que el resto de los edificios, se libraron de «la ira» porque Dios, siguiendo la providencialista interpretación del padre Miguel de Olivares, quiso que quedase en pie para el consuelo y refugio de tan afligido pueblo.

A la mañana siguiente, los penquistas comenzaron a descender de las lomas en que se habían refugiado, e in situ pudieron apreciar y valorar la ruina en que habían quedado convertidas todas sus pertenencias materiales. El obispo, vestido de penitencia, reunió a los vecinos detrás de los muros de una capilla y les dirigió una piadosa exhortación, consolándoles en tanta desgracia y predicándoles la expiación para apaciguar la cólera divina. Tras concluir sus palabras, la ciudad entera hizo voto de sacar en procesión una imagen de Nuestro Señor Jesucristo todas las noches del 15 de marzo,

\footnotetext{
43 Gay (comp.), 1852, II, 243.

44 Rosales, 1877, II, 205.

45 Olivares, 1874, 217.

46 Petit-Breuilh, 2002, 343.
} 
cumpliéndolo religiosamente hasta el terremoto de $1751 ;{ }^{47}$ no obstante, durante esta nueva tragedia, nadie se preocupó de comprender el origen de las causas físicas del evento, ni menos asociaron la reiteración del funesto acontecimiento al emplazamiento de Concepción.

\section{¿Se pensó en el traslado de la ciudad?}

La nueva catástrofe produjo una profunda impresión en todos los ánimos e incitó el desaliento entre los colonos ya que, por encontrarse totalmente disipados y repartidos entre las estancias y haciendas vecinas ${ }^{48}$, comenzaron a hacer más latente la creencia de que aquellos nefastos acontecimientos eran una señal incuestionable de que era voluntad divina que los españoles no dominaran el territorio allende el Maule; además de ser un castigo evidente por las faltas acumuladas y el anuncio de nuevos desastres. Sumábanse a estas sombrías percepciones la falta de recursos económicos para reedificar la ciudad y los fuertes arruinados, por lo que los habitantes de la destrozada urbe y las tropas que protegían la frontera del sur de Chile pronto se verían acosados por el frío y el hambre.

Esa mísera situación obligó a muchos a pensar que la ruina de aquel Reino era prácticamente irreparable, por lo que fue opinión común abandonar todos los territorios situados al sur del Maule y establecer sobre este río una línea fronteriza que los españoles no debían traspasar. Esta era al menos la opinión de los miembros de la Audiencia de Santiago, manifestada oficialmente al rey en el comunicado que el fiscal don Alonso de Solórzano y Velasco redactó en la mencionada capital del Reino de Chile tras recibir noticias de la catástrofe penquista.

Conbendra -decía ese escrito- despoblar la ciudad de Concepción, dejándola fortificada con solo 200 soldados, haciendo mejor y mas segura mancion que ya se bieron despobladas en otra ocasión las ciudades de la Imperial, Villa-Rica y Angol, Osorno y aora la de Chillan, y dejar (des)poblada la de Chillán y pasar sus armas á el partido de la ribera de Maule, poblando en Duao, país capaz de buen temple y muy fértiles aquellas riberas, donde se guardara el vado que el río abre allí, tiene gran comodidad para el riego de tierras. ${ }^{49}$

47 Carvallo y Goyeneche, 1875, II, 119.

48 Archivo General de Indias (AGI), Chile, 61, s/f, el obispo de Santiago al rey, Santiago, 16 de marzo de 1664.

49 Gay (comp.), 1852, II, 442-443. 
El mensaje de fondo que contenía aquel oficio era que el territorio de Chile estaba prácticamente perdido, y que los medios para su restauración resultaban absolutamente ineficaces, ya sea por la escasez de habitantes, de recursos económicos o por la fuerza y vigor de los indígenas; sin embargo, a pesar de la minuciosa y razonada exposición, en ninguna línea del citado documento se atiende al comportamiento de la naturaleza.

A la luz de aquella propuesta, y en el ánimo del rey y de sus consejeros, claramente quedaba desprestigiada la labor del gobernador, don Pedro Porter Casanate. En este sentido, hay que decir que en la Corte española aún se mantenía intacta la creencia del poder ilimitado de las armas reales, entendiéndose que los desastres ocurridos en Chile eran el resultado de un mal gobierno, por ende, la negativa situación se mejoraría sustituyendo a las autoridades de turno. Es por ello que, y a pesar del poco auspicioso escenario, Porter Casanate continuó con la recuperación del territorio perdido, intentando restablecer la paz y la tranquilidad comprendida entre los ríos Maule y Biobío.

Pedro Porter, que estaba fuera de Concepción el día de la ruina, volvió a ella tan pronto como tuvo noticias del terremoto, apresurándose para ponerla en estado de defensa, temiendo, una vez más, que los indígenas se aprovecharan del caos y de la consternación de sus habitantes. Su sola presencia, sumada a la llegada de algunas fragatas con víveres, reanimaron a los afligidos pobladores de Concepción quienes, a pesar de la desnudez y escasez de comidas en que les dejó el terremoto, no pensaron jamás en abandonar su ciudad. Así, ayudados por los socorros que les fueron enviados por el cabildo santiaguino, comenzaron a reconstruir sus arruinadas habitaciones, las cuales, transcurrido un año de la catástrofe, estaban en su gran mayoría habitables, permitiéndole a la urbe poder recobrar una existencia aparentemente normal y tranquila. Martín Herize y Salinas, quien por entonces era corregidor de ella, expresó en su obra lo siguiente:

finalmente puedo y debo afirmar que con estos felices progresos del señor Gobernador se ha restaurado mucha parte de lo perdido, así en la rebelión, como en el terremoto y reflujo que padeció Penco; porque si hemos de juzgar por los efectos, se reconoce que las iglesias y conventos se reedifican, el culto divino y celebración de fiestas se frecuenta con mucho lucimiento, las casas se reparan y se hacen otras de nuevo, los caminos están seguros, los vecinos se alientan a poblar y restituir sus

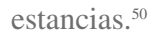

50 Herize y Salinas, 1879, XIII, 319. 
Siguiendo el comentario de este funcionario, puede entenderse que el hecho de que los vecinos no hayan pensado en ningún momento abandonar su ciudad se explique porque en ellos estaba arraigado de un modo profundo el espíritu de los colonizadores, una energía que, según Herize y Salinas, les impedía abandonar su lugar de residencia habitual, aún ante la perspectiva de obtener riquezas, incluso menos sacrificadas, en otro lugar.

\section{El terremoto de 1730, un freno al desarrollo}

Durante los primeros años del siglo XVIII, Concepción comenzó a experimentar una serie de importantes cambios no sólo en su fisonomía, sino también con relación a su papel como capital militar del país. Esta situación se debió fundamentalmente a que, tras el terremoto de 1657, la guerra empezó a perder intensidad y entró en una etapa de tregua no concertada que dio paso a una convivencia más fluida en las relaciones fronterizas, originando una reducción de la estructura castrense a favor de las relaciones comerciales hispano-indígenas. En este contexto, y a modo de ejemplo, la declinación del período bélico se apreció en la disminución del Real Situado que llegaba a Concepción, ya que su envío, desde 1688, se hizo directamente desde Potosí, sin pasar por las Cajas Reales limeñas, agilizando su recepción; esto se tradujo en una ferviente relación comercial mercantil entre los soldados del ejército y los comerciantes de profesión. ${ }^{51}$ Además, la presencia de navíos franceses, que bajo pretexto de las alianzas creadas con la Corona española originaron una importante red de contrabando, ayudaron a modificar y darle vida al puerto y a la ciudad en su conjunto. ${ }^{52}$

Lo concreto es que Concepción se comenzó a transformar al ritmo de las nuevas circunstancias. Una de ellas, y quizás la de mayor impacto, fue el desarrollo del comercio cerealero que se tradujo en importantes cambios en la estructura comercial exportadora al crecer notablemente el sector agrícola sobre el ganadero. Resultado de lo anterior, la ciudad militar, que había resistido los enfrenamientos bélicos y que se había logrado levantar luego de dos paroxismos de origen geológico, quedaba relegada por la ciudad civil; sin embargo, el rápido proceso de crecimiento y desarrollo que

51 Mazzei, 1985, 20.

52 Campos Harriet, 1964, 158. 
presentaba el asentamiento se vio obstaculizado, nuevamente, por la acción desenfrenada de la naturaleza.

El 8 de julio de 1730, un nuevo terremoto que afectó a todo el territorio chileno se hizo sentir con más fuerza en las ciudades del sur, y en forma especial en Concepción, donde el movimiento sísmico fue acompañado de una serie de salidas del mar que la dejaron en la más absoluta ruina. Ésta sería la tercera catástrofe natural que la destruía.

Aquel movimiento telúrico, que se produjo a la una y media de la mañana, ${ }^{53}$ fue calificado como «uno de los más terribles estremecimientos de la tierra esperimentado en América», ${ }^{54}$ y el tsunami que lo acompañó provocó, una vez más, dramáticas descripciones de llanto y desolación. Según el testimonio del obispo penquista Francisco Antonio de Escandón, después del seísmo y hasta las primeras horas de la madrugada, el mar se retiró durante cuatro o cinco oportunidades siendo:

\section{la retirada, y la salida y cada una con mas impetuosa fuerza, especialmente la terce- ra, en que, como a las tres de la mañana, se volvió a repetir el temblor de tierra, aun con mayor duración y con tan violentos vaivenes que pareció quería arroxar de si a todos los mortales. ${ }^{55}$}

Las olas del mar que, siguiendo el lenguaje e interpretaciones de la época, no se contuvieron en los términos que Dios les señaló, entraron en la ciudad más de tres manzanas o cuadras tierra adentro (unos quinientos metros), barriendo con sus embates todo lo que el temblor había dejado en pie, ${ }^{56}$ infligiendo en la urbe la más absoluta desolación. El jesuita Miguel de Olivares lo evocó así:

retirándose el mar por tres veces, tres veces volvió con mas furia con todo el peso de aquellos montes de agua; i salvando la playa se entró sin resistencia por la ciudad y arruinó mas de doscientas casas que estaban situadas en lo mas bajo de la población i cerca de la playa. ${ }^{57}$

53 AGI, Chile, 145, 32, el gobernador Gabriel Cano y Aponte al virrey del Perú, Lima, 20 de octubre de 1730 .

54 Carvallo y Goyeneche, 1875, II, 253.

55 AGI, Chile, 145, 1, el obispo de Concepción al rey, Concepción, 20 de agosto de 1730.

56 Pérez García, 1900, II, 357.

57 Olivares, 1874, 219. 


\title{
Los daños y las enmiendas
}

Si se intentan analizar los perjuicios ocasionados por la catástrofe, bien se puede afirmar, siguiendo la documentación, que fueron mayores a los ocurridos en 1657, principalmente porque la inundación provocada por el tsunami se extendió mucho más tierra adentro, afectando a un mayor número de construcciones. Ahora, si se consideran las mejores condiciones socioeconómicas de los nuevos vecinos, en comparación con los del siglo anterior, resulta lógico pensar que los edificios se habían alzado con más calidad y lujo, con lo cual la pérdida resultaba de mayor cuantía. El obispo Francisco Antonio de Escandón lo resumió de la siguiente manera:

\begin{abstract}
dexo arruinadas de las tres partes, las dos de sus templos, sus casas y sus edificios, llevándose consigo cuanto encontró dentro de ellos, y lo que no pudieron sacar las ondas lo dejó sepultado en sus ruinas. Cayó todo el Convento de San Francisco, menos la iglesia que quedo maltratada, que será forzoso derribarla. El de San Agustín cayo tan del todo que solo se pudo sacar, con gran peligro el Santísimo Sacramento. La Iglesia, el Hospital de San Juan de Dios, se arruinó [...] A un mismo tiempo se arruinó cayendo a plomo, el Palacio de los Governadores; lo mismo le sucedió al mío; por estar uno, y otro los mas cercanos al mar. Cayeron las Caxas Reales, la Sala de Armas y Municiones, la Veeduria general, la Guardia principal, los cuarteles de Cavalleria, e Infanteria, las Casas del Ayuntamiento, las Carzeles públicas. Y en suma, de tres partes, las dos, de las mas principales casas y edificios de esta ciudad con los Graneros, las Bodegas, y tiendas de Mercaderías. ${ }^{58}$
\end{abstract}

Siguiendo su pormenorizada descripción, no es difícil poder imaginarse el estado de la ciudad a la mañana siguiente, el cual acentuaba aún más el grado de aislamiento y el sentimiento de desamparo. Así los penquistas, que como en las ocasiones anteriores, escaparon hacia los cerros aledaños, se quedaron admirados al ver como todo el sector que llamaban Canta-Ranas, que era el más cercano a la playa, «estaba a un nivel con el agua de la bahía, i que todo era mar i que el mar había perdido sus orillas». ${ }^{59}$ Como consecuencia del terremoto, y especialmente por las inundaciones marítimas, los pobladores quedaron sin albergue, sin ropa, sin muebles ni víveres, ya que - continuando con la escena descrita por Escandón - «en medio de este mar nadaban sus haciendas de ropa y cuanto tenían en sus casas y aun las mismas casas, porque los que eran ranchos de madera de

58 AGI, Chile, 145, 2, el obispo de Concepción al rey, Concepción, 20 de agosto de 1730.

59 Olivares, 1874, 220. 
algunos pobres, las arrancó el agua y se las llevó». ${ }^{60}$ Por lo tanto, el resultado de aquel proceso geológico combinado dio origen a fervorosos actos de piedad, además de todo tipo de comentarios, ya que el vulgo, como era común ante este tipo de eventos, se ocupó de referir anécdotas que indicaban que el pueblo tenía plena conciencia de que aquel terremoto era la consecuencia de sus innumerables excesos; ${ }^{61}$ y aunque el obispo, distinguido hombre de letras, no estaba de acuerdo con esta aseveración, no perdonó diligencia alguna para fomentar el recogimiento de sus afligidos y «culpables» devotos.

De este modo, el citado prelado se dedicó a predicar en los cerros, donde estaban refugiados los habitantes penquistas, poniendo de manifiesto un hecho que consideramos importante: la capacidad o virtud para aceptar íntegramente la condición que identifica a Dios como fuente de castigos y principio de misericordia. Sin embargo, tal como lo indica el mismo Escandón, la perfección de Dios no sólo va reducida a castigar y hacer justicia, sino que también implica la piedad de la misericordia, una suerte de dialéctica en cuanto a la transformación de algo negativo en su anverso positivo. En este sentido, se puede inscribir el siguiente comentario del insigne clérigo:

Se reconciliaron muchos enemigos; se han unido los matrimonios separados; se han casado muchos, que vivian mal amigados: se han hecho muchas restituciones: han sido grandes demostraciones de públicas penitencias. ${ }^{62}$

Como se puede desprender de aquellas líneas, el temor que imprimió el violento terremoto en la población preparó los ánimos para oír las fuertes reconvenciones que la religión dirigió a sus fieles, y esa misma aprehensión les hizo dóciles para ejecutar las amonestaciones y reformar sus costumbres, por lo que no resulta curioso constatar cómo Concepción se transformaría por una suerte de encanto, ya que, a la vez que su exterior se veía ocupado por montones de escombros y casas a medio caer, el interior de sus habitantes, es decir, su espíritu, concebía «las resoluciones generosas de arreglos en las costumbres». ${ }^{63}$

En este contexto, y procurando no desatender las funciones de la administración pública, las autoridades civiles dictaron urgentes medidas

60 Idem.

61 Eyzaguirre, 1850, II, 353.

62 AGI, Chile, 145, 6, el obispo de Concepción al rey, Concepción, 20 de agosto de 1730.

63 Eyzaguirre, 1850, II, 353. 
para agilizar los trabajos de reparación, ya que la catástrofe había dejado a la mayoría de los penquistas no sólo sin techo, sino también sin víveres. Intentando aliviar la grave situación, el cabildo santiaguino ordenó que se trajesen provisiones de las estancias vecinas, fijándole los precios en nombre del interés público, a fin de que la desgracia común no diera origen a despiadadas especulaciones. Así, y con los auxilios enviados desde Santiago y Lima, prontamente se comenzó la reconstrucción de aquella ciudad, sin que nadie se detuviera a pensar en la posibilidad de buscar un sitio más adecuado para su emplazamiento.

\section{La ruina final y el obligado traslado}

Concepción no se alcanzaba a recuperar de los estragos sufridos tras el terremoto de 1730, cuando otra vez fue asolada por la naturaleza. Esta nueva catástrofe, la cuarta de su historia, sería decisiva para el emplazamiento de la ciudad, ya que el terremoto y tsunami de 1751 la dejaron en la más absoluta ruina, evocando las proféticas palabras el gobernador Cano y Aponte que, tras el desastre anterior, había concluido que la restauración del Reino «llevaría tanto tiempo que sería imposible de ver por quienes vivenciaron aquel fenómeno». ${ }^{64}$

A este respecto, las crónicas y los documentos de la época abundan en patéticas descripciones, pero antes de conocerlas, quizás resulte interesante apreciar el estado de la ciudad previo al cataclismo. El padre Gabriel Guarda, basándose en planos y documentos inobjetables recopilados durante su larga trayectoria investigadora, expuso que el tsunami que se generó tras el sismo privó a sus habitantes de una ciudad que, debido a su original desarrollo, añorarían con nostalgia, dada la alta jerarquía de la urbe y su peculiar desenvolvimiento. ${ }^{65}$ El habitante y espectador de aquel excepcional recinto, siguiendo su completa descripción:

remontaba desde el sur la calle principal, paralela al mar, lo hacia partiendo de la plazuela de Santo Domingo, contigua al convento de este título; a escasos metros de este cenobio, a su derecha veía abrirse una pequeña plazuela flanqueada por el palacio episcopal, el seminario conciliar y la Catedral, que presentaba a lo largo del total de

64 AGI, Chile, 145, 32, el gobernador Gabriel Cano y Aponte al virrey del Perú, Lima, 20 de octubre de 1730 .

65 Guarda, 1968, 76. 
uno de sus constados los contrafuertes de la nave de la Epístola. Avanzando siempre por la misma calla, el transeúnte pasaría frente al hastial de ese magnifico edificio y entraría por el ángulo sur a la gran Plaza Mayor, que, sin embargo, tampoco ni siquiera ocupaba dos solares enteros. Dinamizaban los costados de este recinto al norte de las casas del Cabildo, al oriente la Compañía de Jesús, con una callejuela anexa que irrumpía casa a eje en la plaza y al poniente casas principales. ${ }^{66}$

Lo cierto es que aquel trabajado conjunto urbano se desplomaría, literalmente, de la noche a la mañana, negando los notables progresos arquitectónicos y técnicos de la colonia. La madrugada del 25 de mayo del citado año, a la una y media de la mañana, se experimentó un fortísimo terremoto que, con una duración de seis minutos ${ }^{67}$ puso en la mayor consternación a toda la población del Reino. Aunque el sacudimiento del suelo no fue tan violento como en las otras ocasiones descritas, su larga duración y a la hora en que ocurría, habrían bastado para sembrar el pánico. Entendiendo que la ruina del territorio era general, el activo Domingo Ortiz de Rozas (17461755) denunció que «Dios quería apiadarse deste Reyno, y sacarnos del temor y sosobras a que nos ha constituido este aviso de su Justicia». ${ }^{68}$

Previo a este terremoto, la noche del 23 de mayo, entre las once y doce de la noche, se había sentido un fuerte remezón de tierra que llenó de sobresaltos a los moradores. ${ }^{69}$ En consecuencia, los habitantes de Concepción, a lo menos en su mayoría, consideraron este movimiento como un aviso misericordioso y se mantuvieron en vigilia toda la noche, dispuestos a abandonar sus habitaciones a la primera señal de peligro, hasta que:

Llego el día 25 de dicho mes referido, día verdaderamente funesto, y horroroso para esta infelicísima Ciudad, en que no olvidando Dios de su piedad, entre la una y dos de la mañana, empezó la tierra a estremecerse de manera que todos despertaron para ponerse en salvo; y pasada una muy breve interrupción, arreció el Temblor de tal manera, y con tanta extraña violencia, que aún el mantenerse en pie, era no poco difícil.. ${ }^{70}$

Los atribulados penquistas, que a esas horas estaban entregados al sueño, al sentir tal movimiento salieron corriendo por las calles, elevando al cielo sus peticiones de clemencia y perdón. Las continuas réplicas en medio de la oscuridad reinante, y los obstáculos en que se convirtieron los

66 Ibidem, 77.

67 AGI, Chile, 146, 8, el gobernador Domingo Ortiz de Rosas al virrey del Perú, Santiago, 8 de mayo de 1751 .

68 Idem.

69 Gay (comp.), 1852, II, 484.

70 Anónimo, 1756, XV, 406. 
numerosos escombros, ya que se «habían derribado templos y edificios sin reserva de casa alguna», ${ }^{71}$ dejaron a muchos sin la posibilidad inmediata de escapar, y la sensación del eventual avance del mar se conjugaba para dificultar la huida hacia los encumbrados cerros.

Los temblores, que según las descripciones se sucedían como en una ópera macabra, no dejaron templo ni casas en pie, suscitando los más extraños y profundos lamentos que se puedan excogitar. En este sombrío escenario una narración refiere que, cuando se comenzó a vociferar sobre la posible salida del mar, muchos huyeron hacia los cerros sin más guía que su propio miedo, y «sin cuidar nadie más que de si propio: duplicando la pena de los padres y madres por no saber de sus hijos, ni maridos de sus mugeres, huían sin mas cuidado, que alexarse». ${ }^{72}$ La desesperación y el caos llevaron a muchos penquistas a pensar que no llegarían a vivir la mañana siguiente; por otra parte, otros relatos indican que mientras todos los acongojados ánimos discurrían y comenzaban a hacer propia esta fatal idea, mostró Dios una de sus mayores maravillas «y fue el haber detenido las aguas del mar algo mas de media hora después del temblor», ${ }^{73}$ tiempo necesario para que la población pudiera, aunque con la descrita dificultad, escapar y guarecerse en los cerros, cuyas faldas también comenzaban a desmoronarse a consecuencia del movimiento telúrico. Lo cierto es que a la media hora del seísmo, el mar:

se ausento precipitadamente de sus riberas dejando toda su bahía (que es de 3 leguas) en seco, pero como a los siete minutos volvió con grandísima fuerza encrespando ola sobre ola con tanta altura que excediendo sus limites supuro y corono toda la bahía. ${ }^{74}$

El último cataclismo, «y del que puedo hablar como testigo ocular» ${ }^{75}$ dice el jesuita Felipe Gómez de Vidaurre, «arruinó completamente la Concepción, no quedando en ella edificio alguno, que pudiere servir a su dueño». ${ }^{76}$ En efecto, sus habitantes, al más mínimo movimiento sísmico, rápidamente, y basándose en las experiencias anteriores, corrían hacia los

71 AGI, Audiencia de Chile, 146, 13, informe del marqués de Salinas al virrey del Perú, Lima, 9 de agosto de 1751 .

72 Anónimo, 1756, XV, 408.

73 Gay (comp.), 1852, II, 487.

74 Ibidem, 488.

75 Gómez de Vidaurre, 1889, I, 66. En la introducción realizada por Diego Barros Arana a la obra de Gómez de Vidaurre, y basándose en datos biográficos, indica que este autor tenía once años cuando fue testigo de aquella tragedia.

76 Idem. 
cerros para poder salvar sus vidas; en este sentido, el abate Juan Ignacio Molina, en sus Elegías a la ruina de Concepción, reveló que:

\footnotetext{
Desde ese momento, ni el sexo, ni la vejes cansada son freno, ni el camino acobardo al enfermo. Todos huyen al mismo tiempo, el miedo les dio alas y el solícito amor por la vida los hizo diligentes [...] Cada uno busca y se decide únicamente por su huida [...] No hay quien piense en su riqueza abandonada. No hay quien repare en nada de lo que quede en la ciudad. ${ }^{77}$
}

Esta última cita, serviría para entender por qué el número de fallecidos no superó las treinta personas, ${ }^{78}$ de las cuales «seis eran inválidas, un loco que se entregó al mar y tres que no creían en los terremotos». ${ }^{79}$ No obstante, para los sobrevivientes el escenario volvía a ser desolador, ya que nuevamente quedaron sin albergue, sin ropa ni comida pero — siguiendo algunas de las místicas elucidaciones-, como la divina misericordia les permitió encontrar entre el barro y los escombros una gran cantidad de peces muertos y trigo, pudieron sobrevivir hasta que se llegase la ayuda proveniente de la región central de Chile. En consecuencia, la evaluación de aquella catástrofe fue completamente desfavorable. Un anónimo testigo la sintetizó de la siguiente manera:

por más que alguna ligera pluma haya querido disminuir su estrago, pues mirada de extremo a extremo, no ha quedado casa en ella, que pueda sin gran recelo, habitarse..$^{80}$

Por su parte, el abate Molina concluyó que:

todo lo que para el ornato había encontrado una época espléndida, lo rompió aquel terremoto o lo pudrió el lodo. ${ }^{81}$

Aquellos simbólicos y fatídicos juicios se entienden debido a que en «Penco el temblor lo dejó todo arruinado, todos los templos y las casas». ${ }^{82}$ Por ejemplo, la iglesia Catedral, que después del terremoto de 1730 había sido reconstruida de cal y ladrillo, quedó completamente arruinada; el templo de Santo Domingo también resultó destruido en su totalidad, y de la iglesia de San Francisco, situada más cerca de la playa, no quedó resto

77 Molina, 1997, 35.

78 Gay (comp.), 1852, II, 491.

79 Gómez de Vidaurre, 1889, 67.

80 Anónimo, 1756, XV, 412.

81 Molina, 1997, 27.

82 Vergara Quiroz (comp.), 1987, 16. 
alguno. ${ }^{83}$ Esa misma desdicha la experimentaron las fábricas de la Merced, de San Agustín, el Hospital de San Juan de Dios y el cenobio de las Trinitarias Descalzas, único convento de religiosas en la ciudad. ${ }^{84}$ Asimismo, cayeron dos establecimientos educacionales: el seminario y el convictorio, y los edificios episcopales y reales; y, siguiendo el citado relato anónimo, ninguna cosa hizo más patente el espantoso terremoto, que el daño provocado en la floreciente edificación del colegio de la Compañía de Jesús que, construido de piedra y ladrillo, era «el mejor que había por su fábrica en esta ciudad». ${ }^{85}$ Por último, en lo que respecta a las viviendas particulares, la destrucción - sin considerar los ranchos pajizos de los habitantes más pobres- se elevó a más de 250 casas. ${ }^{86}$

Resultado de lo anterior, muchos de los angustiados habitantes, al verse sin techo ni comida, y al evocar los otros daños que les había causado este irreconciliable enemigo, comenzaron a clamar por mudarse a otro sitio en que se considerasen libres de su acción. En este sentido, el gobernador Ortiz de Rosas, consciente del peligro y la presión de los penquistas, determinó, no sin antes despertar una larga y apasionada polémica que se dilató durante doce años ${ }^{87}$ el traslado de la ciudad al Valle de la Mocha, un sitio distante a unos 16 kilómetros al sur de Penco. ${ }^{88}$

Aquel traslado — que finalmente se ordenó el día 4 de marzo de 1764 y se ejecutó entre enero y marzo del año siguiente— ${ }^{89}$ significó un grave paréntesis en el desarrollo urbano de la ciudad, limitando enormemente sus posibilidades de convertirse en un polo que contrapesara la preeminencia e importancia de la región central del país, ayudando así a consolidar a Santiago como el centro urbano por excelencia y como la capital financiera del Reino de Chile. A este respecto, y como colofón al traslado, el cronista Vicente Carvallo y Goyeneche advirtió que: «sus habitantes fueron separados de su justamente amado y delicioso terreno en que nacieron y conducidos al árido valle de la Mocha, cuyo suelo es todo de arena». ${ }^{90}$

\footnotetext{
83 Cox Méndez, 1892, 217.

84 AGI, Chile, 146, 204, sor Rita de Santa Gertrudis, abadesa de la Santa Trinidad al gobernador, Concepción, mayo de 1751.

85 Anónimo, 1756, XV, 415.

86 Mazzei, 1985, 27.

87 Las alternativas del traslado se encuentran ampliamente desarrolladas en Campos Harriet, 1982, 257-275. Mazzei, 1985, 29-41. Musset, 2010, 42-53.

88 Sobre el origen del nombre del Valle de la Mocha, y su emplazamiento y características geográficas, ver: Campos Harriet, 1974, 12-15.

89 Campos Harriet, 1982, 274.

90 Carvallo y Goyeneche, 1875, III, 96.
} 


\section{Consideraciones finales}

El mundo penquista, desde finales del siglo XVI hasta las primeras dos décadas del siglo XVIII, fue sacudido por tres seísmos que, con epicentros en el fondo marino, generaron tsunamis que arrasaron toda su costa, destruyendo lo que se había construido por los conquistadores hasta esa fecha (en 1570, 1657 y 1730). Después de cada uno de estos terremotos y sus respectivos tsunamis y corrimientos de tierra, la población quedó dispersa, malviviendo entre las ruinas y en las lomas de los cerros cercanos; sin embargo, el despoblamiento de la ciudad no se ejecutó, ya fuera por la persistencia de los gobernadores de turno, o bien por el profundo espíritu colonizador que animaba a sus habitantes. No obstante, tras la última catástrofe, ocurrida en mayo de 1751, se decidió, tal como se ha referido, el traslado definitivo de la ciudad.

San Agustín, en su homilía De urbis excidio referente a la devastación de Roma, señaló que cuando Dios castiga al género humano y lo acosa piadosamente con sus flagelos, castiga al mismo tiempo a justos e injustos. ${ }^{91}$ De acuerdo con las palabras del santo latino, tras originarse un movimiento telúrico, la devoción, que adquiría renovados bríos, tenía muchas ocasiones de manifestarse con el claro propósito de expiar las culpas que eran consideradas las causantes de la catástrofe, y de esta forma ganar la caridad y la gracia divina. Así se explica que, después de cada arrojo de la naturaleza, abundaran las confesiones, rezos del rosario, novenas, la prédica de sermones edificantes y moralizantes, además de las procesiones de penitencia; a lo anterior, se sumaba el recato en las vestimentas para evitar los excesos que, según la mentalidad de la época, habían contribuido a provocar la ira de Dios.

Las desdichas, las angustias, la calamidad y la muerte que padeció el pueblo penquista se atribuyó ciertamente a la desobediencia de los preceptos divinos; de este modo, en los escritos de uno de los tantos protagonistas se lee lo siguiente: «fue la majestad divina servida de embiar por mis pecados un tan grande terremoto que no dejo piedra sobre piedra». ${ }^{92}$ Confesiones como la citada abundan en los archivos de la época, pero en prácticamente ningún escrito se refleja algún tipo de preocupación por intentar entender las causas mismas del fenómeno que tanto daño les causó.

91 San Agustín, 1995, XL, 517.

92 AGI, Chile, 146, 200, Thomas de Carmona al gobernador, Arauco, Concepción, 25 de mayo de 1751. 
Un terremoto es un peligro natural, y bien se puede transformar en una catástrofe cuando el ser humano desatiende a sus causas y desafía las reglas de la naturaleza; no obstante, nuestros ancestros ante cualquier movimiento del suelo creían ver fenómenos de todo tipo, interpretándolos de las más diversas y apocalípticas maneras, haciendo todo tipo de promesas para reformar sus vidas, mejorar sus costumbres y así intentar aplacar la ira divina. Un curioso escrito teológico, representante del modo de discernir de aquellos tiempos, planteó lo siguiente respecto al origen de los seísmos «causados por los pecados de los hombres»:

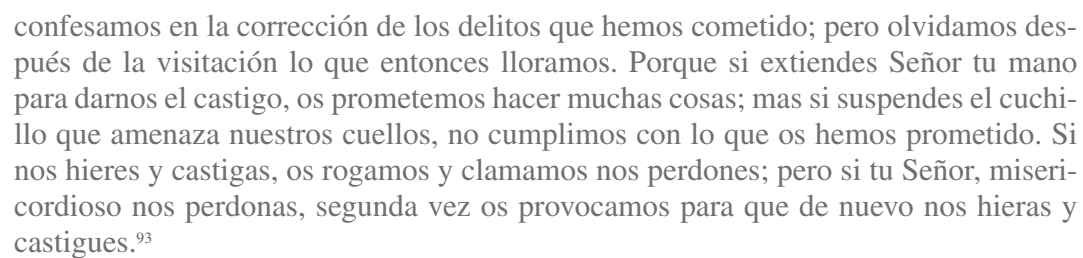

No conforme con este argumento, Felipe Gómez de Vidaurre, así como otros religiosos y letrados, intentaron darle alguna explicación más racional a los fenómenos telúricos, exponiendo hipótesis como las siguientes:

la subterránea efervescencia de las materias inflamables, de que está compuesta la masa del territorio chileno, rarefaciendo la elasticidad del aire, y reduciendo a vapores la prodigiosa fuerza del agua que del mar vecino se introduce por los conductos subterráneos, causa inmediatamente tal fatal acontecimiento y así, concluye, yo vengo a concebir los terremotos como algunos físicos modernos creen deber suponer. ${ }^{94}$

Esta última reflexión demuestra que, ya para mediados del siglo XVIII, muchos compartían la idea de que los terremotos eran procesos físicos propios de la naturaleza, y no un castigo enviado por Dios a las provincias del sur por sus escándalos públicos y la corrupción de sus habitantes; sin embargo, muchos personajes, fundamentalmente políticos y eclesiásticos, se esmeraban en perpetuar la idea del castigo divino con la intención de mantener, sin alteraciones, el régimen social y teocrático de la colonia. El citado escrito teológico así lo reafirma:

93 Guzmán, 1836, II, 767.

94 Gómez de Vidaurre, 1889, I, 65. 
no negaré a ningún filósofo ni estudioso que los temblores de tierra sean efectos naturales pero al mismo tiempo puede ser también que Dios se valga de estos fieles ejecutores de su voluntad santísima para castigar los pecados de los pueblos..$^{95}$

Concluyendo, y dejando a un lado la discusión teórica sobre el origen de los sismos, sus estragos siempre han resultado ser perjudiciales para los intereses de la sociedad que los experimenta, obligándole a estar constantemente prevenida para atenuar los efectos de una catástrofe; en este sentido, y considerando que la ciudad de Concepción logró reconstruirse después de cada desastre, cobran validez las palabras de San Agustín, especialmente cuando señaló que «una ciudad está en sus habitantes, no en sus murallas». ${ }^{96}$ Así, el viejo Penco, dominado y castigado duramente por la naturaleza, a treinta años de la catástrofe de 1751 se mostraba, frente a los ojos de los viajeros, como un pequeño valle cubierto por paredes y tapiales fragmentados, donde apenas se podía apreciar la disposición de sus principales calles y edificios, siendo la fachada de la Compañía de Jesús el único vestigio reconocible de la que fue considerada, en su tiempo de máximo esplendor, una ciudad modelo. ${ }^{97}$

Recibido el 25 de enero de 2011 Aceptado el 06 de febrero de 2012

\section{Bibliografía}

Alberola, Armando: «La natura desfermada: al voltant de manuscrits, impresos i imatges sobre desastres naturals en l'Espanya del segle XVIII», en Alberola, Armando; Olcina, Jorge. (eds.): Desastre natural, vida cotidiana y religiosidad popular en la España moderna y contemporánea, Alicante, Universidad de Alicante, 2009, 17-76.

Amunátegui Solar, Domingo: El cabildo de Concepción: 1782-1818, Santiago, Establecimientos Gráficos Balcells, 1930.

Anónimo: «Relación de lo que sucedió en la ciudad de la Concepción de Chile con el temblor e invasión del mar, el día 25 de mayo de 1751 entre la una, y dos de la mañana», en Davin, Diego (comp.): Cartas edificantes, y curiosas, escritas de las Missiones Estrangeras, XV, Madrid, Imprenta de la Viuda de Manuel Fernández y del Supremo Consejo de la Inquisición, 1756, 406-422.

95 Guzmán, 1836, II, 764.

96 San Agustín, 1995, XL, 525.

97 Haenke, 1942, 173. 
Barros Arana, Diego: Historia jeneral de Chile, Santiago, Rafael Jover Editor, 1884, 1-6.

Briseño, Ramón: Repertorio de antigüedades chilenas, Santiago, Imprenta Gutenberg, 1889.

Calderón, Georgina: «Lo ideológico de los términos en los desastres», Revista Geográfica de América Central, 47-II, Costa Rica, 2011, 1-16.

Campos Harriet, Fernando: Veleros franceses en el mar de sur, Santiago, Editorial Zig-Zag, 1964.

Campos Harriet, Fernando: Leyendas y tradiciones penquistas, Santiago, Editorial Orbe, 1974.

Campos Harriet, Fernando: «Fundaciones, refundaciones y traslado de Concepción del Nuevo Extremo en el Reino de Chile», VI Congreso Internacional de Historia de América, Buenos Aires, Academia Nacional de la Historia, 1982, 257-275.

Campos Harriet, Fernando: Historia de Concepción, 1550-1970, Santiago, Talleres Gráficos de la Universidad Técnica del Estado, 1979.

Carvallo y Goyeneche, Vicente: Descripción histórico-jeográfica del Reino de Chile, Santiago, Imprenta La Estrella de Chile, 1875, 3 vols.

Córdoba y Figueroa, Pedro de: Historia de Chile (1492-1717), Santiago, Imprenta del Ferrocarril, 1862.

Cox Méndez, Guillermo: Obras escogidas, Santiago, Imprenta Barcelona, 1892.

Espinoza, Guillermo: «El manejo de los desastres naturales: conceptos y definiciones básicas aplicadas a Chile», Medio Ambiente y Urbanización, 30, Buenos Aires, 1990, 21-30.

Eyzaguirre, José Ignacio Víctor: Historia eclesiástica, política y literaria de Chile, Valparaíso, Imprenta del Comercio, 1850, 3 vols.

García, Virginia: «Enfoques teóricos para el estudio histórico de los desastres naturales», en García, Virginia (coord.): Estudios históricos sobre desastres naturales en México: balance y perspectivas, México, Centro de Investigaciones y Estudios Superiores en Antropología Social, 1992, 19-32.

Gascón, Margarita: «Los desastres naturales en las ciudades latinoamericanas», Entelequia. Revista Interdisciplinar, 2, Málaga, 2006, 263-270.

Gay, Claudio (comp.): Historia física y política de Chile. Documentos sobre la historia, la estadística y la geografía de Chile, Santiago, Museo de Historia Natural de Santiago, 1852, 2 vols.

Gómez de Vidaurre, Felipe: Historia geográfica, natural y civil del Reino de Chile, Santiago, Imprenta Ercilla, 1889, 2 vols.

Góngora y Marmolejo, Alonso de: Historia de Chile desde su descubrimiento hasta el año de 1575, Santiago, Imprenta del Ferrocarril, 1862.

González de Nájera, Alonso: Desengaño y reparo de la guerra del Reino de Chile, Santiago, Imprenta Ercilla, 1889. 
Guarda, Gabriel: La ciudad chilena del siglo XVIII, Buenos Aires, Centro Editor de América Latina, 1968.

Guarda, Gabriel: Historia urbana del Reino de Chile, Santiago, Editorial Andrés Bello, 1978.

Guzmán, José Javier: El chileno instruido en la historia topográfica, civil y política de su país, Santiago, Imprenta Araucana, 1836, 2 vols.

Haenke, Tadeo: Descripción del reino de Chile, Santiago, Editorial Nascimento, 1942.

Herize y Salinas, Martín: «Felices progresos que las armas de Su Majestad han conseguido en el reino de Chile desde 31 de diciembre del año pasado de 1657 hasta el presente de 1658», en Sancho Rayón, José (comp.): Colección de libros españoles raros ó curiosos, XIII, Madrid, Imprenta de Miguel Ginesta, 1879, 279-236.

Herzer, Hilda: «Los desastres no parecen tan naturales como parecen», Medio Ambiente y Urbanización, 30, Buenos Aires, 1990, 4-10.

Hipona, San Agustín de: Obras Completas, Madrid, Biblioteca de Autores Cristianos, 1995, XL.

Kordic, Raïssa: «El terremoto de 1730 visto por el Obispo de Concepción Francisco Antonio de Escandón», Cuadernos de Historia, 10, Santiago, 1990, 209-225.

Lahore, Juan: «El Decenio Internacional para la Reducción de los Desastres Naturales», Primer Congreso Iberoamericano sobre Técnicas Aplicadas a la Gestión de Emergencias para la Reducción de Desastres Naturales: Ponencias y Comunicaciones, Valencia, 1992, 1-6.

Mariño de Lobera, Pedro: Crónica del Reino de Chile, Santiago, Imprenta del Ferrocarril, 1865.

Maskrey, Andrew: El manejo popular de los desastres naturales. Estudios de vulnerabilidad y mitigación, Lima, Tecnología Intermedia, 1989.

Maskrey, Andrew; Romero, Gilberto: «Cómo entender los desastres naturales», en Maskrey, Andrew (comp.): Los desastres no son naturales. Bogotá, La Red, 1993, 6-10.

Matus, Pablo (edit.): Enciclopedia regional del Biobío, Santiago, Pehuén Editores, 2005.

Mazzei, Leonardo: Historia del traslado de la ciudad de Concepción, Concepción, Universidad de Concepción, 1985.

Mellafe, Rolando: «El acontecer infausto en el carácter chileno, una proposición de historia de las mentalidades», Atenea, 442, Concepción, 1980, 121-128.

Molin, Helena: «Decenio Internacional para la Reducción de los Desastres Naturales (DIRDN)», en Lavell, Allan (coord.): Viviendo en riesgo: Comunidades vulnerables y prevención de desastres en América Latina, Bogotá, La Red, 1994, 361-367. 
Molina, Juan Ignacio: Compendio de la historia geográfica, natural y civil del reyno de Chile, Madrid, Imprenta de Antonio de Sancha, 1788, 2.

Molina, Juan Ignacio: Elegías a la ruina de Concepción, Santiago, Imprenta de la Biblioteca Nacional de Chile, 1997.

Musset, Alain: «Vulnerabilidad social, justicia espacial y resiliencia: Concepción, Chile, entre dos terremotos 1751-1835», en Musset, Alain (coord.): Ciudad, sociedad, justicia: un enfoque espacial y cultural, Mar del Plata, Editorial de la Universidad Nacional de Mar del Plata, 2010, 31-64.

Olivares, Miguel de: Historia de la Compañía de Jesús en Chile (1593-1736), Santiago, Imprenta Andrés Bello, 1874.

Oliver Schneider, Carlos: Libro de oro de la historia de Concepción, Concepción, Litografía Concepción, 1950.

Organización de las Naciones Unidas (ONU): Vivir con el riesgo: Informe mundial sobre iniciativas para la reducción de desastres, s/e, 2004.

Palacios Roa, Alfredo: «El gran terremoto de 1730: la experiencia santiaguina frente a la catástrofe», Temas Americanistas, 22, Sevilla, 2009a, 1-18.

Palacios Roa, Alfredo: «La sensibilidad religiosa frente a las catástrofes naturales», en Sánchez, Marcial (coord.): Historia de la Iglesia en Chile: En los caminos de la conquista espiritual, Santiago, Imprenta Universitaria, 2009b, 345-367.

Pérez García, José: Historia natural, militar, civil y sagrada del Reino de Chile, Santiago, Imprenta Elzeviriana, 1900, 2.

Petit-Breuilh, María Eugenia: «La ira de Dios: religiosidad y terremotos en Ayamonte durante el siglo XVIII», IV Jornadas de Historia de Ayamonte, Huelva, Patronato Municipal de Cultura de Ayamonte, 1999, 257-271.

Petit-Breuilh, María Eugenia: «Conjuros y exorcismos ante los desastres naturales en Hispanoamérica (siglos XVI-XVIII)», Actas del Segundo Encuentro Iberoamericano de Costumbres Populares, Huelva, Centro de Estudios Rocieros, 2002, 331-351.

Petit-Breuilh, María Eugenia: Desastres naturales y ocupación del territorio en Hispanoamérica: (siglos XVI al XX), Huelva, Universidad de Huelva, 2004.

Petit-Breuilh, María Eugenia: Naturaleza y desastres en Hispanoamérica: la visión de los indígenas, Madrid, Silex Ediciones, 2006.

Risopatrón, Luis: Diccionario jeográfico de Chile, Santiago, Imprenta Universitaria, 1924.

Rodríguez, Alfredo: «Desastres urbanos, fenómenos no-naturales», Medio Ambiente y Urbanización, 30, Buenos Aires, 1990, 11-20.

Rosales, Diego de: Historia general del Reino de Chile, Valparaíso, Imprenta del Mercurio, 1877, 3.

Thayer Ojeda, Tomás: «Las antiguas ciudades de Chile: apuntes históricos sobre su desarrollo i listas de los funcionarios que actuaron en ellas hasta el año 1565», Anales de la Universidad de Chile, CXXIX, Santiago, 1911, 754-884. 
Valdivia, Pedro de: Cartas de Pedro de Valdivia: que tratan del descubrimiento y conquista de Chile, Sevilla, Establecimientos Tipográficos de M. Carmona, 1929.

Vargas, Jorge: Políticas públicas para la reducción de la vulnerabilidad frente a los desastres naturales y socio-naturales, Santiago, Comisión Económica para América Latina y el Caribe (CEPAL), 2002.

Vergara Quiroz, Sergio (comp.): Cartas de mujeres en Chile, Santiago, Editorial Andrés Bello, 1987.

Vivar, Gerónimo de: Crónica y relación copiosa y verdadera de los reinos de Chile, Santiago, Fondo Histórico y Bibliográfico José Toribio Medina, Instituto Geográfico Militar, 1966. 